\title{
An inducible transgene expression system for regulated phenotypic modification of human embryonic stem cells
}

\author{
Ji-Dong Fu ${ }^{1,2}$, Camie WY Chan ${ }^{2,3}$, Ronald $\mathrm{A} \mathrm{Li}^{1,2,3}$ \\ ${ }^{1}$ Stem Cell Program and ${ }^{2}$ Department of Cell Biology and Human Anatomy, University of California Davis, Davis, CA, USA; \\ ${ }^{3}$ Institute of Pediatric Regenerative Medicine, Shriners Hospital for Children of North America, Sacramento, CA, USA
}

Self-renewing pluripotent human (h) embryonic stem cells (ESCs) are capable of regenerating such non-dividing cells as neurons and cardiomyocytes for therapies, and can serve as an excellent experimental model for studying early human development. Both the spatial and temporal relationships of gene expression play a crucial role in determining differentiation; to obtain a better understanding of hESC differentiation, it will be necessary to establish an inducible system in hESCs that enables specific transgene(s) to reversibly and conditionally express $i$ ) at specific levels and ii) at particular time points during development. Using lentivirus (LV)-mediated gene transfer and a tetracycline-controlled trans-repressor (TR), we first established in hESCs a doxycycline (DOX)-inducible expression system of GFP to probe its reversibility and kinetics. Upon the addition of DOX, the percentage of GFP ${ }^{+}$hESCs increased time-dependently: The time at which $50 \%$ of all green cells appeared $\left(T_{50}{ }^{\circ}\right)$ was $119.5 \pm 3.2$ hours; upon DOX removal, GFP expression declined with a half time $\left(T_{50}\right.$ off $)$ of $127.7 \pm 3.9$ hours and became completely silenced at day 8. Both the proportion and total mean fluorescence intensity (MFI) were dose-dependent $\left(E C_{50}=\mathbf{2 4 . 5} \pm 2.2 \mathrm{ng} / \mathrm{ml}\right)$. The same system when incorporated into murine $(\mathrm{m})$ ESCs similarly exhibited reversible dose-dependent responses with a sensitivity similar to hESCs $\left(E C_{50}=49.5 \pm 8.5 \mathrm{ng} / \mathrm{ml}\right)$ but the kinetics were much faster $\left(\mathrm{T}_{50}{ }^{{ }^{\mathrm{n}}}=35.5 \pm 5.5 \mathrm{hours}\right.$, $\mathrm{T}_{50}{ }^{\text {off }}=\mathbf{7 1 . 5} \pm 2.4$ hours). DOX-induced expression of the Kir2.1-encoded inwardly rectifying $\mathrm{K}+$ current rendered the resting membrane potential of $m$ and $h$ ESCs hyperpolarized. We conclude that the LV inducible system presented here enables investigators to dose-dependently control the level of target gene expression at specific time points in hESCs during their differentiation.

Keywords: human embryonic stem cells, differentiation, doxycycline, lentivirus

Cell Research (2008) 18:s133. doi: 10.1038/cr.2008.223; published online 4 August 2008

Correspondence: Ronald Li

E-mail: ronaldli@ucdavis.edu 